\title{
Individual and demographic consequences of reduced body condition following repeated exposure to high temperatures
}

\author{
Janet L. Gardner,,${ }^{1,2,5}$ Tatsuya Amano, ${ }^{3}$ William J. Sutherland,${ }^{3}$ Mark Clayton, ${ }^{4}$ and Anne Peters ${ }^{1}$ \\ ${ }^{1}$ School of Biological Sciences, Monash University, Melbourne, Vic. 3168, Australia \\ ${ }^{2}$ Division of Evolution, Ecology and Genetics, The Australian National University, Canberra, ACT 0200, Australia \\ ${ }^{3}$ Conservation Science Group, Department of Zoology, University of Cambridge, Cambridge, CB2 3EJ, United Kingdom \\ 481 Maribyrnong Avenue, Kaleen, ACT 2617, Australia
}

\begin{abstract}
Although the lethal consequences of extreme heat are increasingly reported in the literature, the fitness costs of exposure to sublethal high air temperatures, typically identified in the $30-40^{\circ} \mathrm{C}$ range, are poorly understood. We examine the effect of high $\left(\geq 35^{\circ} \mathrm{C}\right)$ daily maxima on body condition of a semiarid population of White-plumed Honeyeaters, Ptilotula penicillatus, monitored between 1986 and 2012. During this 26-yr period, temperature has risen, on average, by $0.06^{\circ} \mathrm{C}$ each year at the site, the frequency of days with thermal maxima $\geq 35^{\circ} \mathrm{C}$ has increased and rainfall has declined. Exposure to high temperatures affected body condition of White-plumed Honeyeaters, but only in low-rainfall conditions. There was no effect of a single day of exposure to temperatures $\geq 35^{\circ} \mathrm{C}$ but repeated exposure was associated with reduced body condition: $3.0 \%$ reduction in body mass per day of exposure. Rainfall in the previous $30 \mathrm{~d}$ ameliorated these effects, with reduced condition evident only in dry conditions. Heat-exposed males with reduced body condition were less likely to be recaptured at the start of the following spring; they presumably died. Heat-exposed females, regardless of body condition, showed lower survival than exposed males, possibly due to their smaller body mass. The higher mortality of females and smaller males exposed to temperatures $\geq 35^{\circ} \mathrm{C}$ may have contributed to the increase in mean body size of this population over 23 years. Annual survival declined across time concomitant with increasing frequency of days $\geq 35^{\circ} \mathrm{C}$ and decreasing rainfall. Our study is one of few to identify a proximate cause of climate change related mortality, and associated long-term demographic consequence. Our results have broad implications for avian communities living in arid and semiarid regions of Australia, and other midlatitudes regions where daily maximum temperatures already approach physiological limits in regions affected by both decreased precipitation and warming.
\end{abstract}

Key words: body condition; climate change; demographic change; mechanism; Meliphagidae; mortality; semiarid; sublethal temperatures; temperature extremes; White-plumed Honeyeater.

\section{INTRODUCTION}

Despite numerous studies providing correlative evidence for the effects of climate change on the distributions, phenology, and morphology of species, few identify proximate causes of demographic change (Cahill et al. 2013, Ockendon et al. 2014, Selwood et al. 2014). The consequences for demography of exposure to extreme temperatures is gaining increasing attention in the literature given forecasts of global increases in the frequency and intensity of extreme climatic events (Boyles et al. 2011, Easterling et al. 2001, McKechnie et al. 2012). Much research has focused on the lethal consequences of extreme heat. Exposure to high temperatures, above critical thresholds, has been shown to cause mass mortalities in a range

Manuscript received 9 April 2015; revised 6 August 2015; accepted 14 September 2015. Corresponding Editor: G. A. Nevitt.

${ }^{5}$ E-mail: janet.gardner@anu.edu.au of taxa including endotherms and ectotherms (Cerrano et al. 2000, Easterling et al. 2000, Welbergen et al. 2008, Saunders et al. 2011, McKechnie and Wolf 2012).

Birds may be particularly vulnerable to the effects of extreme temperatures due to their relatively high body temperatures, small body sizes, and predominantly diurnal habits (Scholander et al. 1950, Boyles et al. 2011, McKechnie and Wolf 2012). In birds, lethal hyperthermia occurs when body temperatures exceed about $45^{\circ} \mathrm{C}$ (McKechnie and Wolf 2010, Boyles et al. 2011). McKechnie and Wolf (2010) modelled the effects of increasing maximum temperatures on avian water balance during extremely hot conditions and argued that mortality events for birds inhabiting hot deserts will become increasingly frequent under future climate scenarios. Smaller individuals and species are particularly vulnerable because the relatively larger surface area to volume ratios that characterize smaller individuals, and allow more effective dumping of heat loads in warmer conditions, may become 
disadvantageous under short-term exposure to extreme heat; larger surface areas result in disproportionate rates of evaporative water loss, with smaller birds more vulnerable to acute dehydration and mortality (McKechnie and Wolf 2012).

Less well understood are the fitness costs of exposure to sublethal air temperatures, typically identified as temperatures in the $30^{\circ}-40^{\circ} \mathrm{C}$ range (McKechnie et al. 2012). High temperatures have been shown to affect nestling development and foraging ecology with negative consequences for body condition and fitness. For example, for Southern Fiscals, Lanius collaris, in the Kalahari, increasing exposure to high temperatures $\left(33^{\circ}-37^{\circ} \mathrm{C}\right)$ during the nestling period affected chick development, reducing fledgling body mass and tarsus length, and delaying fledging date, all of which have negative effects on survival (Cunningham et al. 2013a). Similarly, adult Southern Pied Babblers, Turdoides bicolor, were unable to maintain body mass when daily air temperatures exceeded $35.5^{\circ} \mathrm{C}$, because individuals did not gain sufficient mass during the day to compensate for normal overnight mass loss that occurs due to fasting (du Plessis et al. 2012). Because reduced body condition can compromise survival and reproductive success, du Plessis et al. (2012) concluded that short-term exposure to extreme heat might be harmless but repeated exposure is likely to comprise ability to maintain body condition, with negative consequences for fitness.

Body condition may also be involved in driving changes in structural body size that have been correlated with recent rapid climate change (Gardner et al. 2011). Gardner et al. (2014) found that the mean body size of a population of White-plumed Honeyeaters Ptilotula penicillatus had increased over 23 years; this was mainly associated with increases in ambient temperature at the site. Two mechanisms may have been involved. First, as considerable energy is required for the maintenance of high avian body temperatures (Gillooly et al. 2001), a warming climate may reduce the costs of keeping warm leading to improved body condition, and the subsequent production of larger offspring (Gardner et al. 2014). Second, exposure to daily maxima $\geq 35^{\circ} \mathrm{C}$ was associated with larger body size, an effect attributed to size-dependent mortality. Gardner et al. (2014) suggested that the average body size of the population might have increased following mortality of smaller individuals, which are more vulnerable to acute dehydration in heatwave conditions, in accordance with the predictions of McKechnie and Wolf (2010). Despite this possibility, lethal temperatures $>45^{\circ} \mathrm{C}$ are rare at the site ( $3 \mathrm{~d}$ in $23 \mathrm{yr}$ ), so the consequences for fitness of increasing exposure to high temperatures may be mediated via cumulative effects on body condition as proposed by du Plessis et al. (2012), rather than result from immediate mortality from heat stress (McKechnie and Wolf 2010).
Here, we assess this hypothesis by testing the effect of high daily maximum temperatures on the body mass of the White-plumed Honeyeaters over the period 1986-2012 as studied by Gardner et al. (2014). We predicted that:

1. Repeated exposure to temperatures $\geq 35^{\circ} \mathrm{C}$ will have a negative effect on body condition and will be associated with lower survival.

2. Repeated exposure to daily maxima $\geq 35^{\circ} \mathrm{C}$ will have a disproportionate effect on smaller individuals.

3. Rainfall will ameliorate the effects of high temperatures via the provision of free water that can reduce dehydration in hot conditions (McKechnie and Wolf 2012).

4. Long-term trends in survival will be negative, in accordance with temporal increases in temperature and decreasing rainfall at the site (Gardner et al. 2014).

\section{Methods}

Study site and study species

We studied a population of White-plumed Honeyeaters over a 26-yr period (1986-2012) at The Charcoal Tank Nature Reserve, near West Wyalong, in central western New South Wales, Australia $\left(-33.9831^{\circ} \mathrm{S}, 147.1575^{\circ} \mathrm{E}\right)$. Details of the site and population are given in Gardner et al. (2014). In brief, the Reserve comprises an 86-ha remnant of Eucalyptus and Melaleuca woodland, surrounded by wheat fields on all sides, and has three dams providing semipermanent water. The climate has become hotter and drier over the last 26 years at Wyalong. Since 1985, total annual rainfall has declined significantly, temperature has increased by $0.06^{\circ} \mathrm{C}$ on average each year, and the annual frequency of hot days recording maxima $\geq 35^{\circ} \mathrm{C}$ has increased, particularly since 1995 (Gardner et al. 2014).

White-plumed Honeyeaters are a small (14-22 g in this study) widespread Australian passerine species belonging to the large and diverse Meliphagidae (Joseph et al. 2014). Males are larger than females: $18.8 \mathrm{~g}$ $(n=397)$ vs. $16.9 \mathrm{~g}(n=315)$ in this study. The species is primarily nectarivorous, but invertebrate prey forms an important part of the diet, especially for growing young (Ford and Paton 1977). White-plumed Honeyeaters are considered resident or sedentary at the site, although some local movements may occur (Gardner et al. 2014). The annual breeding season usually extends from July to the end of November, with free-flying juveniles captured between October and March each season; late breeding occurs very rarely at the site, with only 2 of 140 juveniles captured outside this period in May. Adults undertake an annual flight feather molt, usually starting in December or 
January following breeding, with birds undertaking their first flight feather molt at the end of their first year of life.

Birds were captured in mist nets two to seven times each year as part of a long-term banding (ringing) program at this site. One of us (M. Clayton) personally directed and supervised data collection over the 26 years of the project and methods were consistent over time. Birds were weighed with a Pesola balance to an accuracy of $0.5 \mathrm{~g}$ and the primaries were scored for molt. Wing length, an index of structural body size, was measured as the length of the flattened wing chord to the nearest $1.0 \mathrm{~mm}$ using a butt-ended ruler. Among passerines, wing length is the best single linear predictor of structural size, and accordingly may be used as an index of body size (Gosler et al. 1998).

Birds in their first three months of life and first-year birds can be distinguished from adults on the basis of plumage (Gardner et al. 2014); we only included adults in this study. The sexes could be separated on differences in head-bill lengths with males larger than females (Gardner et al. 2014).

\section{Statistical analysis}

Data We selected data for adults captured between October and March inclusive (1986-2010) to eliminate the effect of cold winter days (those below $0^{\circ} \mathrm{C}$; May-August) that can affect body size (Krams et al. 2012). We excluded any bird in flight feather molt. We calculated environmental variables from climate data, based on standardized daily records from the Wyalong (Station 073054, West Wyalong Post office; $33.93^{\circ} \mathrm{S}, 147.24^{\circ} \mathrm{E}$ ) weather station (Bureau of Meteorology), located $10.5 \mathrm{~km}$ from the study site. We extracted the maximum temperature on the day before capture for each individual, hereafter called initial exposure. To assess the effect of repeated exposure to high temperatures, we calculated the number of days with maxima $\geq 35^{\circ} \mathrm{C}$ to which each bird had been exposed in the $7 \mathrm{~d}$ prior to initial exposure. We also extracted the amount of rainfall that fell on the day before capture for each individual as well as that recorded in the $30 \mathrm{~d}$ prior to capture; we used a 30-d period based on evidence of a 1-month lag between rainfall and food availability that affected reproduction in a semiarid bird (Illera and Díaz 2006).

Models 1. Effects of climate on body condition.-We investigated the effect of maximum daily temperature on body mass by constructing linear mixed models with body mass as the response variable. We fitted both linear and quadratic terms for maximum temperature on the day before capture (initial exposure) as explanatory variables because we predicted that increasing body mass will be associated with increasing daily maximum temperature, up to about $35^{\circ} \mathrm{C}$, due to reductions in the thermoregulatory costs of keeping warm (Introduction), but the positive effect on body mass will be reversed with exposure to temperatures $\geq 35^{\circ} \mathrm{C}$. We also tested for the effects of repeated exposure to high temperatures by fitting the number of days with maxima $\geq 35^{\circ} \mathrm{C}$ to which each bird had been exposed in the $7 \mathrm{~d}$ prior to initial exposure. As the provision of free water can reduce dehydration in hot conditions, we fitted rainfall recorded on the day of initial exposure as an additional variable (McKechnie and Wolf 2010). Rainfall is also associated with increased food availability, particularly in arid climates, so birds exposed to high temperatures following periods of high rainfall may be in better condition, and therefore cope better with high temperatures (Brown and Sherry 2006). Hence, we also fitted total rainfall recorded in the $30 \mathrm{~d}$ prior to initial exposure. Because the distribution of rainfall was bimodal in our data set we fitted the term as a categorical variable, high $(\geq 35 \mathrm{~mm})$ vs. low $(<35 \mathrm{~mm})$ (Appendix S1: Fig. S1). Finally, as the response of body mass to high temperatures is predicted to be affected by $T_{\max }$ (maximum temperature on the day before capture), plus cumulative effects of exposure to high temperatures in the preceding days (number days $\geq 35^{\circ} \mathrm{C}$ ) as well as recent rainfall (rain 30 last days), we fitted a three-way interaction between these terms, as well as appropriate two-way interactions.

We fitted the identity of individuals as a random term to account for the recaptures of the same individuals over multiple years. We controlled for structural body size using residual wing length, which we calculated from a regression between wing length, abrasion score, sex, and age to account for changes in wing length due to age and feather abrasion. We assigned an index of feather wear to account for abrasion of the tips of primary feathers, which occurs between successive molts and affects wing length (Gardner et al. 2014). We also controlled for month and time (24 h) of capture, both of which are known to affect body mass, and included minimum age, based on recapture information, because effects on body mass may vary with age and experience (Monaghan 2008). Finally we included year of capture to control for factors additional to climate that may affect body mass. All continuous, explanatory variables were centered on their means.

2. Fitness costs of reduced body condition following exposure to high temperatures. - We predicted that individuals with reduced body condition following exposure to high temperatures would have lower survival through the following winter. Based on recapture information, we identified whether individuals survived until the following spring/summer, nominally 1 October (binomial response: yes/no). We used recapture as a proxy for survival because adults known to be alive had a 78\% chance of recapture in each year (Gardner et al. 
2014). For each individual, we assessed survival using recapture information, based on a minimum period of 2 $\mathrm{yr}$ from the date of capture. We tested whether survival (recapture) was affected by body condition for exposed (experienced $\geq 1 \mathrm{~d}$ with temperature $\geq 35^{\circ} \mathrm{C}$ on the day of initial exposure or in the preceding week) and nonexposed (experienced no temperatures $\geq 35^{\circ} \mathrm{C}$ on the day of initial exposure or in the preceding week) individuals using generalized linear models with binomial distributions. Because we lacked data on the proportion of mass lost for each individual we could not directly link exposure, mass loss, and body size. So, instead, we used residual body condition, which estimates energy reserves using size-corrected body mass, calculated by fitting mass as the response variable against residual wing, sex, and time of day. Because the probability of survival may vary with age, sex, body size (residual wing), month, and year of capture we fitted these terms as additional explanatory variables. We also tested whether patterns of survival due to body condition differed between the sexes and with body size by fitting two interaction terms (body condition $\times$ sex, body condition $\times$ residual wing). We selected, at random, one record per individual, and ran separate analyses for individuals that were exposed to daily maxima $\geq 35^{\circ} \mathrm{C}$ and those that were not. We used separate analyses because the structure of our data did not allow us to control for differences in the effect of body condition on survival due to age, sex and size for exposed vs. non-exposed individuals, which would require fitting a prohibitive number of 3-way interaction terms between condition, exposure (yes/no) and each variable, given our sample size.

3. Changes in survival over $26 \mathrm{yr}$ - -We predicted that the survival of individuals would have declined across time given annual increases in the frequency of days recording temperatures $\geq 35^{\circ} \mathrm{C}$ and decline in rainfall at the site (Gardner et al. 2014). We fitted recapture as a proxy for survival as the response variable (as defined in Model 2. Fitness costs of reduced body condition following exposure to high temperatures), and year as an explanatory variable. We controlled for differences in survival due to age and sex. We also fitted an interaction between year $\times$ sex to test whether the temporal pattern of survival differed between the sexes.

Model fitting To avoid multicollinearity among the explanatory variables, we first estimated pair-wise Pearson's correlation coefficients between the explanatory variables (Appendix S1: Table S1) and confirmed that correlations were not high for all the combinations $(|r|<0.28)$. We also calculated variance inflation factors (VIF), which in all cases were $<3$, which is below the threshold recommended by Zuur et al. (2010). To account for model selection uncertainty, we adopted a multi-model inference approach based on the Akaike information criteria corrected for sample size $\left(\mathrm{AIC}_{\mathrm{c}}\right.$; Burnham and Anderson 2002). We first generated a candidate set of models with all possible parameter subsets, which were then fitted to the data and ranked by $\Delta \mathrm{AIC}_{\mathrm{c}}$ values (the difference between each model's $\mathrm{AIC}_{\mathrm{c}}$ and $\mathrm{AIC}_{\mathrm{cmin}}$, that of the "best" model). We reported the top 10 models for each analysis. In each case, the top 10 models include all models with $\triangle \mathrm{AIC}_{\mathrm{c}}$ values $<2$, as well as some models with $\Delta \mathrm{AIC}_{\mathrm{c}}>2$. All analyses were conducted in R 2.15.3 (R Development Core Team 2012), linear mixed models were fitted using the package lme4 (Bates et al. 2012), and generalized linear models were fitted using the MASS package (Venables and Ripley 2002).

\section{RESUlTS}

\section{Factors affecting body condition}

Body mass was affected by temperature and rainfall after controlling for structural size (residual wing length), sex, relative age, time of day, month and year of capture. There was no detectable effect on body mass of maximum temperature on the day before capture in the range $12^{\circ}-41^{\circ} \mathrm{C}$, as this variable was not included in any top models (Table 1). Similarly, rainfall on the day prior to capture had no detectable effect on body mass as this variable was not included in the best model (Table 1). Rather, the effects of temperature and rainfall appeared to be cumulative.

Repeated exposure to days with temperatures $\geq 35^{\circ} \mathrm{C}$ in the $7 \mathrm{~d}$ prior to initial exposure was included in the best model and most of the following top models and the $95 \%$ confidence intervals (CIs) of the estimated coefficient for the best model did not overlap zero; it was associated with reductions in body mass in all cases (Table 1, Fig. 1). However, the effect differed with rainfall conditions (number of days $\geq 35^{\circ} \mathrm{C} \times$ rain $30 \mathrm{~d}$ was included in the best model and most of the following top models and 95\% CIs did not overlap zero in the best model; Table 1, Fig. 1). In the best model, body mass declined by $0.55 \mathrm{~g}$ with each day of exposure to daily maxima $\geq 35^{\circ} \mathrm{C}$ when low rainfall conditions prevailed in the $30 \mathrm{~d}$ prior to capture (Table 1, Fig. 1). In high rainfall conditions, there was no effect on body mass of repeated exposure to temperatures $\geq 35^{\circ} \mathrm{C}$ (Table 1, Fig. 1).

\section{Effects of body condition on survival}

The probability of survival (recapture) differed for exposed and non-exposed individuals. For adults exposed to temperatures $\geq 35^{\circ} \mathrm{C}$ on the day before capture or during the preceding week, those in poorer condition were less likely to be recaptured in the following spring (nominally from 1 October; Table 2a, Fig. 2); body condition was included in all top models (Table 2a). The effect of body condition on recapture did not vary with body size (residual 


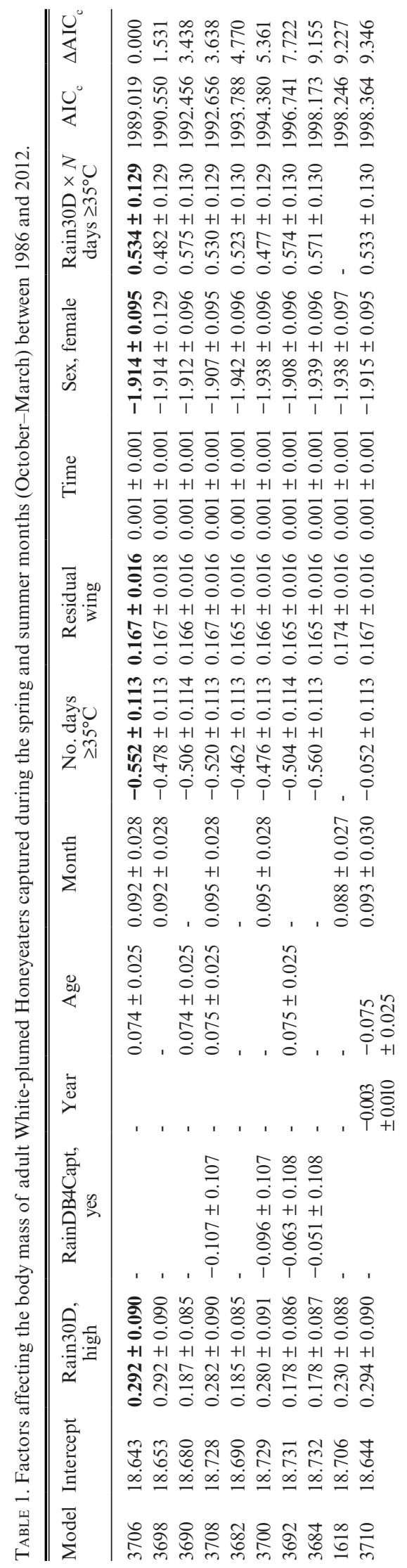

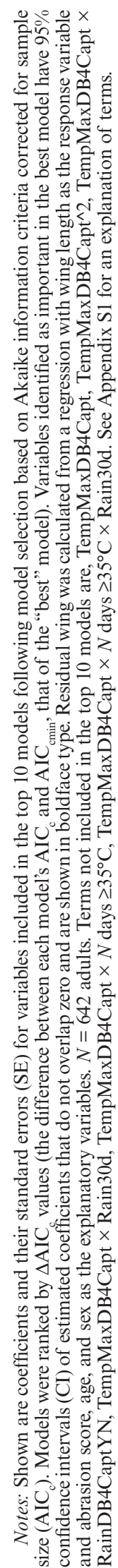

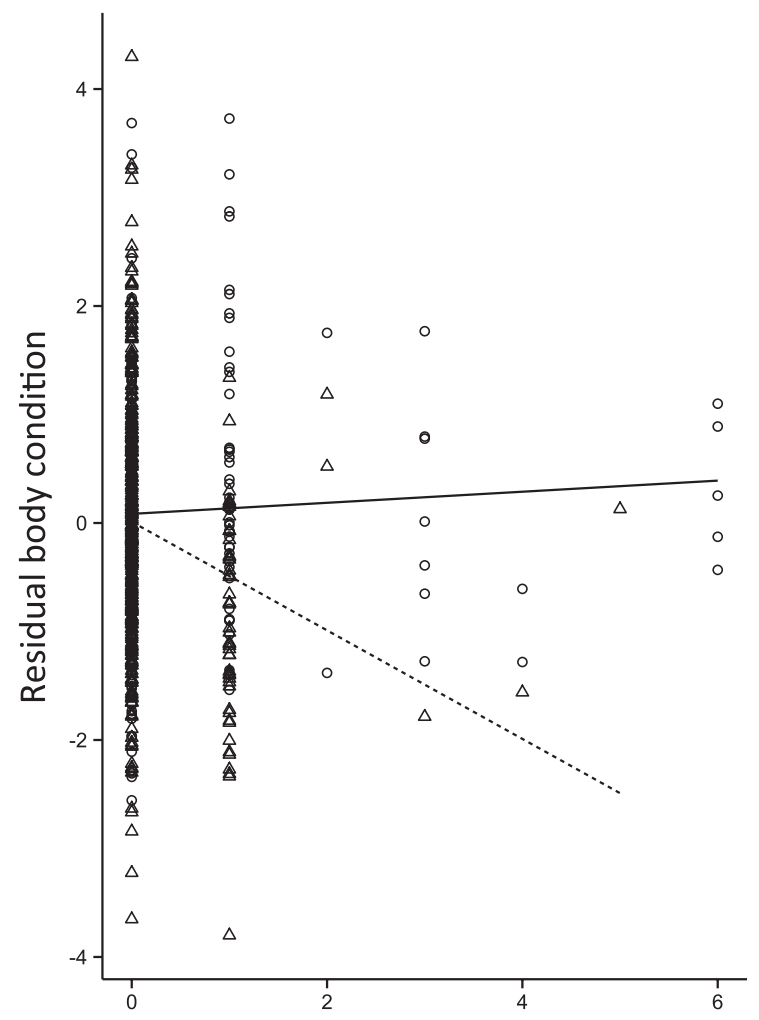

No. days exposed to temperatures $\geq 35^{\circ} \mathrm{C}$

FIG. 1. The effect on body condition of repeated exposure to temperatures $\geq 35^{\circ} \mathrm{C}$ in high (circles, solid line) and low (triangle, dashed line) rainfall conditions. Body condition was calculated as the residuals from a regression with body mass as the response variable and residual wing length, time of capture and sex as the explanatory variables. $N=642$ adults.

condition $\times$ residual wing was not included in the best model or in most top models), but differed between the sexes (residual condition $\times$ sex was included in all top models and $95 \%$ CIs for the coefficient in best model did not overlap zero; Table 2a, Fig. 2). For males, recapture increased with body condition (coefficient in the top model $=0.69$ ), but there was no effect of body condition on the recapture of females (coefficient in the top model $=-0.06$; Table 2a, Fig. 2). Overall, females were less likely to be recaptured than males (sex effect was negative in all top models and the $95 \%$ CIs for the coefficient in best model did not overlap zero; Table 2a).

For adults not exposed to temperatures $\geq 35^{\circ} \mathrm{C}$ on the day before capture or during the preceding week, the probability of recapture in the following spring did not vary with body condition (residual condition effect), nor did the effect of condition vary with sex (residual condition $\times$ sex) or body size (residual condition $\times$ residual wing) as neither of these variables was included in any top model (Table 2b, Fig. 2). Body condition was not included in the best model or in most top models. Further, these two models 


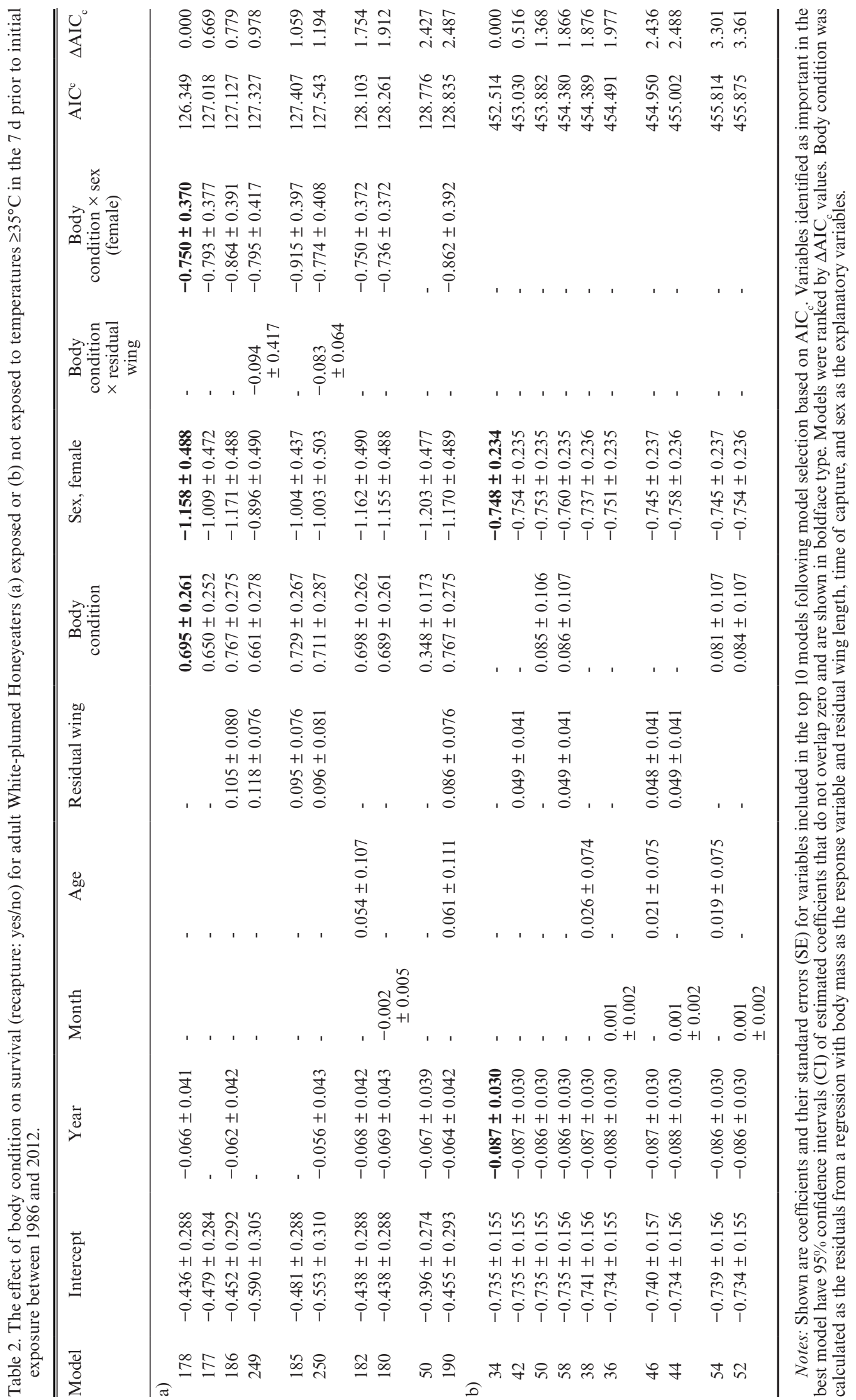


had larger AIC values than the corresponding models without body condition (Appendix S1: Table S3b). Overall, females had a lower chance of recapture than

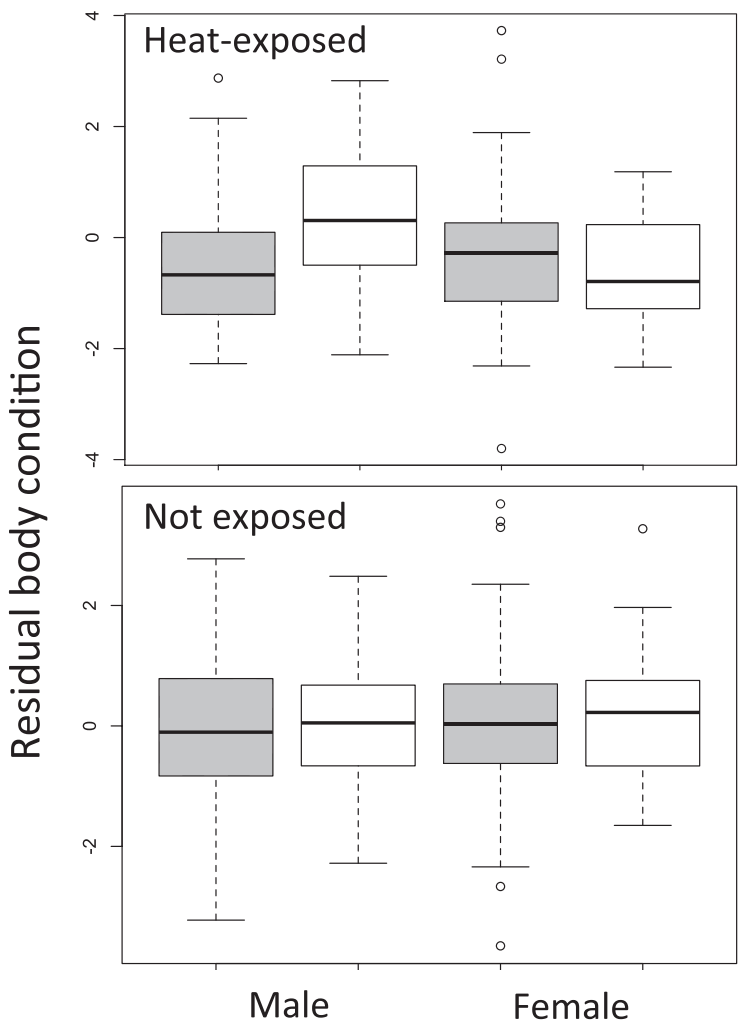

\section{Recaptured}

FIG. 2. The effect of body condition on the probability of recapture at the start of the following spring (nominally 1 October) for male and female White-plumed Honeyeaters exposed, or not, to daily maxima $\geq 35^{\circ} \mathrm{C}$ : gray bars, not recaptured; white bars, recaptured. Body condition was calculated as the residuals from a regression with body mass as the response variable and residual wing length, time of capture, and sex as the explanatory variables. males (sex effect included in all top models and the 95\% CIs for the coefficient in best model did not overlap zero), and the probability of recapture declined across years (year effect included in all top models; the $95 \%$ CIs for the coefficient in best model did not overlap zero; Table 2b, Fig. 2).

\section{Long-term survival over 26 yr}

The probability of survival (recapture) declined over time (year effect was negative in the best model and in all top models in which the term was included; 95\% CIs did not overlap zero in the best model; Table 3). Overall, females had lower survival than males (sex effect for females was negative in the best model and in all top models in which the term was included; 95\% CIs did not overlap zero in the best model; Table 3), but the temporal pattern of survival did not differ between the sexes and there was no effect of minimum age on survival, as these variables were not included in the best model or in the majority of top models (Table 3 ).

\section{DisCUSSION}

Exposure to high temperatures had strong effects on the body condition of White-plumed Honeyeaters, with repeated exposure to temperatures $\geq 35^{\circ} \mathrm{C}$ driving reductions in body mass in low-rainfall conditions. There was no effect of a single day of exposure to daily maxima $\geq 35^{\circ} \mathrm{C}$ but repeated exposure in low rainfall conditions was associated with loss of condition. Rainfall in the $30 \mathrm{~d}$ prior to exposure ameliorated the effects of high temperatures, with mass loss associated only with low rainfall conditions. Heat-exposed (i.e., those that had experienced at least one hot day) males in poorer condition were less likely to be recaptured at the start of the following spring (nominally 1 October) and presumably died. Overall, survival declined over the $26 \mathrm{yr}$ of the study.

TABle 3. Temporal change in survival (recapture: yes/no) for adult White-plumed Honeyeaters captured between 1986 and 2012.

\begin{tabular}{|c|c|c|c|c|c|c|c|}
\hline Model & Intercept & Year & Age & Sex, female & $\begin{array}{l}\text { Year } \times \text { sex } \\
\text { female }\end{array}$ & $\mathrm{AIC}_{\mathrm{c}}$ & $\Delta \mathrm{AIC}_{\mathrm{c}}$ \\
\hline 6 & $-0.638 \pm 0.133$ & $-0.065 \pm 0.023$ & - & $-0.851 \pm 0.208$ & - & 581.127 & 0.000 \\
\hline 8 & $-0.646 \pm 0.134$ & $-0.066 \pm 0.023$ & $0.038 \pm 0.059$ & $-0.838 \pm 0.209$ & - & 582.733 & 1.606 \\
\hline 14 & $-0.637 \pm 0.133$ & $-0.057 \pm 0.028$ & - & $-0.872 \pm 0.214$ & $-0.024 \pm 0.048$ & 582.879 & 1.752 \\
\hline 16 & $-0.644 \pm 0.133$ & $-0.058 \pm 0.028$ & $0.036 \pm 0.059$ & $-0.859 \pm 0.215$ & $-0.022 \pm 0.048$ & 584.518 & 3.391 \\
\hline 5 & $-0.647 \pm 0.132$ & - & - & $-0.789 \pm 0.205$ & - & 588.035 & 6.907 \\
\hline 7 & $-0.653 \pm 0.132$ & - & $0.028 \pm 0.057$ & $-0.777 \pm 0.206$ & - & 589.792 & 8.665 \\
\hline 2 & $-1.025 \pm 0.101$ & $-0.056 \pm 0.022$ & - & - & - & 596.445 & 15.318 \\
\hline 4 & $-1.028 \pm 0.101$ & $-0.057 \pm 0.022$ & $0.062 \pm 0.058$ & - & - & 597.326 & 16.199 \\
\hline 1 & $-1.025 \pm 0.103$ & - & - & - & - & 601.280 & 20.153 \\
\hline 3 & $-1.009 \pm 0.100$ & - & $0.053 \pm 0.056$ & - & - & 602.402 & 21.274 \\
\hline
\end{tabular}

Notes: Shown are coefficients and their standard errors (SE) for variables included in the top 10 models following model selection based on AIC. Variables identified as important in the best model have $95 \%$ confidence intervals (CI) of estimated coefficients that do not overlap zero and are shown in boldface type. Models were ranked by $\Delta \mathrm{AIC}_{\mathrm{c}}$ values. 


\section{Body condition, rainfall, and heat waves}

Our top model estimates mass losses of $3.0 \%$ of body mass per day of exposure to high $\left(35^{\circ}-41^{\circ} \mathrm{C}\right)$ temperatures in low rainfall conditions. Similar rates of mass loss were recorded for semiarid Babblers: overnight mass loss averaged $3.82 \%$ following days with maxima $>30^{\circ} \mathrm{C}$, in low rainfall conditions toward the end of the dry season (du Plessis et al. 2012). In that case, mass loss was associated with a reduction in foraging efficiency such that birds could not gain sufficient energy during hot days to counteract normal overnight mass loss. This study (du Plessis et al. 2012) identified $35.5^{\circ} \mathrm{C}$ as a critical temperature beyond which net mass losses were incurred. Similarly, Cunningham et al. (2013a) recorded changes in body mass and growth in nestling Southern Fiscals when temperatures reached $33^{\circ}-37^{\circ} \mathrm{C}$. Our results are consistent with these studies but definition of threshold temperatures at which fitness costs are incurred requires further study, since critical temperatures are likely to vary among species as well as within, and several thresholds may exist within a single species, each affecting a different correlate of fitness (Cunningham et al. 2013a,b).

Our results provide a rare demonstration of the importance of rainfall in ameliorating individual responses to high temperatures (Bolger et al. 2005, Cahill et al. 2013, Cunningham et al. 2013a,b). Mass loss following repeated exposure to temperatures $\geq 35^{\circ} \mathrm{C}$ occurred only when rainfall in the $30 \mathrm{~d}$ prior to capture was low (Fig. 1). This mass loss could simply represent dehydration: at temperatures above about $30^{\circ} \mathrm{C}$, cooling is achieved via panting and involves evaporative water loss. Birds, such as White-plumed Honeyeaters, that are lighter than about $25 \mathrm{~g}$ are particularly vulnerable due to their relatively large surface-area-to-volume ratios (Wolf 2000, McKechnie and Wolf 2010). However, only when environmental temperatures exceed body temperate (about $40^{\circ} \mathrm{C}$ in birds) do rates of evaporative water loss and dehydration increase dramatically, particularly for small individuals (Dawson and Whittow 2000, Wolf 2000), and in our study, we recorded relatively few days of temperatures above $40^{\circ} \mathrm{C}(115 \mathrm{~d}$ in $26 \mathrm{yr})$. Moreover, rainfall on the day of exposure to high temperatures had no detectable effect on body mass suggesting that dehydration was not the primary factor involved, although several dams at the site that provide semipermanent water may have masked any direct effect of rainfall if birds had access to free water at the time of exposure. Accordingly, we have limited evidence that dehydration was the primary factor driving the negative effects of low rainfall on body condition.

Effects of rainfall on body condition may also be mediated via influence on primary productivity and the resulting quality and quantity of food available with consequences for energy budgets (Albright et al.
2010, Mackey et al. 2012). Body condition can be strongly affected by rainfall-induced variation in food supply with reduced food availability resulting in loss of condition via catabolizing muscle and fat tissue (Brown and Sherry 2006). Indeed, previous analyses showed negative effects of lower rainfall on juvenile growth in this population (Gardner et al. 2014).

High temperatures may also compromise energy budgets by reducing rates of prey capture during the hottest parts of the day or by forcing individuals to reduce or cease foraging altogether to reduce environmental heat loads; such forms of behavioral thermoregulation are almost universal among desert birds (Austin 1976, Wolf 2000, Huey et al. 2012, du Plessis et al. 2012, McKechnie and Wolf 2012; Cunningham et al. $2013 a, b)$. Thus, in low rainfall conditions, the negative effects of high temperatures on energy budgets are likely to be exacerbated because body condition will already be reduced (Brown and Sherry 2006). Whether mass loss in our study was primarily due to failure to balance energy or water budgets or both requires further investigation.

\section{Survival of individuals following exposure to daily maxima $>35^{\circ} \mathrm{C}$}

For individuals exposed to high temperatures, those in poorer condition were less likely to be recaptured and presumably died (Table 2). It is unlikely that these individuals left the study site, as birds in this population are sedentary (Gardner et al. 2014). We estimate mass losses of up to $18 \%$ of body mass, given that some individuals were exposed to six consecutive days with daily maxima $\geq 35^{\circ} \mathrm{C}$, and mass declined by $0.55 \mathrm{~g}$ with each day of exposure. Presumably, our study underestimates effects of exposure to hot days on body condition because banders (ringers) avoid working through extended periods of hot weather due to the risk of bird mortality during capture. Weather records indicate that heatwaves with up to 16 consecutive days of temperatures $\geq 35^{\circ} \mathrm{C}$ were recorded during our study period. Such conditions would result in much higher mass loss (theoretically $48 \%$, excluding time for recovery between episodes), which would likely result in direct mortality (Wolf and Walsberg 1996, Wolf 2000). Understanding the physiological consequences of repeated, rather than acute, exposure to high temperatures and its effects on water and energy budgets is an urgent priority.

Despite immediate survival following repeated exposure to high temperatures, heat-exposed White-plumed Honeyeaters in poorer condition were less likely to be recaptured in the following spring. We suggest that the timing of exposure to heatwaves, during or just prior to molt, may be of critical importance for fitness, magnifying the probability of mortality via delayed, conditiondependent costs on feather molt. It has recently been shown experimentally that the quality of feathers 
produced during molt can be condition dependent, with poor condition associated with slower molt rate and reduced feather quality, leading to the suggestion that feather quality might be a major mediator of life history trade-offs (Dawson et al. 2000, Vágási et al. 2012). Indeed, birds in poor condition due to climate-driven food deprivation suffered carry-over costs on feather growth (Brown and Sherry 2006). Because poor quality plumage impairs insulation and increases thermoregulatory costs, it can lead to lower survival during winter and reduced reproduction in the following year (Nilsson and Svensson 1996, Dawson et al. 2000, Vágási et al. 2012). In White-plumed Honeyeaters, wing molt occurs between December and April each year, immediately after breeding, and increasingly co-occurs with exposure to high temperatures (November-March; Gardner et al. 2014). Energetic constraints are highest during this period of the annual routine, and additional costs on condition imposed by increasing exposure to heatwaves might subsequently affect molt quality with delayed consequences for survival over winter.

Overall, female White-plumed Honeyeaters were less likely to be recaptured than males, regardless of whether they were exposed to high temperatures. In contrast, the survival of heat-exposed males was affected by body condition. That condition-dependent mortality was detected only in males may relate to sex differences in body mass. Females are smaller than males and may be below a critical mass threshold that reduces their capacity to endure the costs of exposure, and only larger males are able to survive. Nevertheless, the higher mortality of (smaller) heat-exposed males and females overall, may have contributed to the temporal increase in mean body size of this population over 23 yr (Gardner et al. 2014).

\section{Population-level trends in survival}

At the population level, survival has declined across time, concomitant with the temporal decline in rainfall and increase in temperature at the site (see Gardner et al. 2014). Given our demonstration of the effects of temperature and rainfall on body condition and its effect on survival we suggest that climate-driven effects on body condition are a contributing factor in the declining survival of this population. Our study thus provides a rare example of a proximate cause of climaterelated variation in individual survival and associated long-term (demographic) consequence (see reviews by Cahill et al. 2013, Ockendon et al. 2014, Selwood et al. 2014). It suggests that selection on heat tolerance may involve exposure to sublethal temperatures with effects on fitness mediated via body condition with consequences for demography and population persistence.

Our results indicate complex, climate-driven changes in demographic rates rather than a direct relationship between mortality and limited tolerance to high temperatures as highlighted by recent studies (Ozgul et al.
2009, Cahill et al. 2013, Ockendon et al. 2014, Selwood et al. 2014). Nevertheless, as the severity of heatwaves increase in the coming years, consistent with the longterm trend at the site (Gardner et al. 2014), direct mortality via acute exposure to extreme heat is also likely, particularly given the trend for declining rainfall. Finally, our study has broad implications for avian communities living in arid and semiarid regions of Australia and other mid-latitude regions characterized by daily maximum temperatures that are already close to known physiological limits in regions that are most affected by decreased precipitation, as well as by warming (e.g. South Africa; see du Plessis et al. 2012, Cunningham et al. 2013a; IPCC 2013).

\section{ACKNOWLEDGMENTS}

The work was conducted under permits SL100167 and SL100825 issued by the Office of Environment and Heritage, National Parks and Wildlife Service (NPWS), NSW and bands were supplied by the Australian Bird and Bat Banding Scheme. We thank the many volunteer banders and NPWS staff for support. Jim Thompson provided initial statistical advice and Loeske Kruuk, Peter Marsack and Katherine Selwood useful discussion or comments on the manuscript. The work received funding from the Norman Wettenhall Foundation and the Australian Research Council (ARC, Discovery grant DP120102651). W. J. Sutherland is funded by Arcadia, A. Peters by an ARC Future Fellowship (FT110100505), and T. Amano by a Marie Curie International Incoming Fellowship.

\section{Literature Cited}

Albright, T. P., A. M. Pidgeon, C. D. Rittenhouse, M. K. Clayton, C. H. Flather, P. D. Culbert, B. D. Wardlows, V. C. Radeloff.2010. Effects of drought on avian community structure. Global Change Biology 16:2158-2170.

Austin, G. T. 1976. Behavioral adaptations of the Verdin to the desert. Auk 93:245-262.

Bates, D., M. Maechler and B. Bolker. 2012. lme4: Linear mixed-effects models using S4 classes R package. http:// cran.r-project.org/web/packages/lme4/index.html

Bolger, D. T., M. A. Patten, and D. C. Bostock. 2005. Avian reproductive failure in response to an extreme climatic event. Oecologia 142:398-406.

Boyles, J. G., F. Seebacher, B. Smit, and A. E. McKechnie. 2011. Adaptive thermoregulation in endotherms may alter responses to climate change. Integrative and Comparative Biology 51:676-690.

Brown, D. R., and T. W. Sherry. 2006. Food supply controls the body condition of a migrant bird wintering in the tropics. Oecologia 149:22-32.

Burnham, K. P., and D. R. Anderson. 2002. Model selection and multimodel inference: a practical information theoretic approach. Second edition. Springer, Berlin, Germany.

Cahill, A. E., M. E. Aiello-Lammens, M. C. Fisher-Reid, X. Hua, C. J. Karanewsky, et al. 2013. How does climate change cause extinction? Proceedings of the Royal Society B 280:20121890.

Cerrano, C., et al. 2000. A catastrophic mass-mortality episode of gorgonians and other organisms in the Ligurian Sea (North western Mediterranean), summer 1999. Ecology Letters 3:284-293.

Cunningham, S. J., A. C. Kruger, M. P. Nxumalo, and P. A. R. Hockey. 2013a. Identifying biologically meaningful 
hot-weather events using threshold temperatures that affect life-history. PLoS ONE 8:e82492.

Cunningham, S. J., R. O. Martin, C. L. Hojem, and P. A. R. Hockey. 2013b. Temperatures in excess of critical thresholds threaten nestling growth and survival in a rapidly-warming arid savanna: a study of common fiscals. PLoS ONE 8:e74613.

Dawson, W. R., and G. C. Whittow. 2000. Regulation of body temperature. Pages 343-390 in P. D. Sturkie, editor. Avian physiology. Academic Press, New York, New York, USA.

Dawson, A., S. A. Hinsley, P. N. Ferns, R. H. C. Bonser, and L. Eccleston. 2000. Rate of moult affects feather quality: a mechanism linking current reproductive effort to future survival. Proceedings of the Royal Society B 267:2093-2098.

du Plessis, K. L., R. O. Martin, P. A. R. Hockey, S. J. Cunningham, and A. R. Ridley. 2012. The costs of keeping cool in a warming world: implications of high temperatures for foraging, thermoregulation and body condition of an arid-zone bird. Global Change Biology 18:3063-3070.

Easterling, D. R., G. A. Meehl, C. Parmesan, S. A. Changnon, T. R. Karl, and L. O. Mearns. 2000. Climate extremes: observations, modeling, and impacts. Science 289:2068-2074.

Ford, H. A., and D. C. Paton. 1977. The comparative ecology of ten species of honeyeaters in South Australia. Australian Journal of Ecology 2:399-407.

Gardner, J. L., A. Peters, M. R. Kearney, L. Joseph, and R. Heinsohn. 2011. Declining body size: a third universal response to warming? Trends in Ecology and Evolution 26:285-291.

Gardner, J. L., T. Amano, B. G. Mackey, W. J. Sutherland, M. Clayton, and A. Peters. 2014. Dynamic size responses to climate change: prevailing effects of rising temperature drive long-term body size increases in a semi-arid passerine. Global Change Biology 20:2062-2075.

Gillooly, J. F., J. H. Brown, G. B. West, V. M. Savage, and E. L. Charnov. 2001. Effects of size and temperature on metabolic rate. Science 293:2248-2251.

Gosler, A. G., J. J. D. Greenwood, J. K. Baker, and N. C. Davidson. 1998. The field determination of body size and condition in passerines: a report to the British Ringing Committee. Bird Study 45:92-103.

Huey, R. B., M. R. Kearney, A. Krockenberger, J. A. M. Holtum, M. Jess, and S. E. Williams. 2012. Predicting organismal vulnerability to climate warming: roles of behaviour, physiology, and adaptation. Philosophical Transactions of the Royal Society B 367:1665-1679.

Illera, J. C., and M. Díaz. 2006. Reproduction in an endemic bird of a semiarid island: a food-mediated process. Journal of Avian Biology 37:447-456.

IPCC. 2013. Summary for policy makers. Climate change 2013: the physical science basis. Contribution of Working Group I to the Fifth Assessment Report of the Intergovernmental Panel on Climate Change Pages 1-30 in T. F. Stocker, D. Qin, G.-K. Plattner, M. Tignor, J. S. Allen, J. Boschung, A. Nauels, Y. Xia, V. Bex, and P. M. Midgley, editors. Cambridge University Press, Cambridge, UK.

Joseph, L., A. Toon, A. S. Nyari, N. W. Longmore, K. M. C. Rowe, T. Haryoko, J. Trueman, and J. L. Gardner. 2014. A new synthesis of the molecular systematics and biogeography of honeyeaters (Passeriformes: Meliphagidae) highlights biogeographical complexity of a spectacular avian radiation. Zoologica Scripta 43:235-248.

Krams, I., D. Cirule, J. Vrublevska, A. Nord, M. J. Rantala, and T. Krama. 2012. Nocturnal loss of body reserves reveals high survival risk for subordinate great tits wintering at extremely low ambient temperatures. Oecologia 172:339-346.

Mackey, B., B. Berry, S. Hugh, S. Ferrier, T. D. Harwood, and K. J. Williams. 2012. Ecosystem greenspots: identifying potential drought, fire, and climate-change micro-refuges. Ecological Applications 22:1852-1864.

McKechnie, A. E., and B. O. Wolf. 2010. Climate change increases the likelihood of catastrophic avian mortality events during extreme heat waves. Biology Letters 6:253-256.

McKechnie, A. E., P. A. R. Hockey and B. O. Wolf. 2012. Feeling the heat: Australian landbirds and climate change. EMU 112:i-vii.

Monaghan, P. 2008. Early growth conditions, phenotypic development and environmental change. Philosophical Transactions of the Royal Society Series B 363:1635-1645.

Nilsson, J. A., and E. Svensson. 1996. The cost of reproduction a new link between current reproductive effort and future reproductive success. Proceedings of the Royal Society B 263:711-714.

Ockendon, N., et al. 2014. Mechanisms underpinning climatic impacts on natural populations: altered species interactions are more important than direct effects. Global Change Biology 20:2221-2229.

Ozgul, A., S. Tuljapurkar, T. G. Benton, J. M. Pemberton, T. H. Clutton-Brock, and T. Coulson. 2009. The dynamics of phenotypic change and the shrinking sheep of St. Kilda. Science 325:464-467.

R Development Core Team. 2012. R: a language and environment for statistical computing. R Foundation for Statistical Computing, Vienna, Austria. http://www.R-project.org/

Saunders, D. A., P. Mawson, and R. Dawson. 2011. The impact of two extreme weather events and other causes of death on Carnaby's Black Cockatoo: a promise of things to come for a threatened species? Pacific Conservation Biology 17:141-148.

Scholander, P. F., R. Hock, V. Walters, F. Johnson, and L. Irving. 1950. Heat regulation in some arctic and tropical mammals and birds. Biological Bulletin 99:237-258.

Selwood, K. E., M. A. McGeoch, and R. Mac Nally. 2015. The effects of climate change and land-use change on demographic rates and population viability. Biological Reviews 90:837-853. doi:10.1111/brv.12136.

Vágási, I. C., P. L. Pap, O. Vincze, Z. Benk, A. Marton, and Z. Barta. 2012. Haste makes waste but condition matters: molt rate-feather quality trade-off in a sedentary songbird. PLoS ONE 7:e40651.

Venables, W. N., and B. D. Ripley. 2002. Modern applied statistics with S. Fourth edition. Springer, New York, New York, USA.

Welbergen, J. A., S. M. Klose, N. Markus, and P. Eby. 2008. Climate change and the effects of temperature extremes on Australian flying foxes. Proceedings of the Royal Society B 275:419-425.

Wolf, B. 2000. Global warming and avian occupancy of hot deserts; a physiological and behavioral perspective. Revista Chilena de Historia Natural 73:395-400.

Wolf, B. O. and G. E. Walsberg, 1996. Respiratory and cutaneous evaporative water loss at high environmental temperatures in a small bird. The Journal of Experimental Biology 199:451-457.

Zuur, A. F., E. N. Leno, and C. S. Elphick. 2010. A protocol for data exploration to avoid common statistical problems. Methods in Ecology and Evolution 1:3-14.

\section{SUPPORTING INFORMATION}

Additional supporting information may be found in the online version of this article at http://onlinelibrary.wiley.com/ doi/10.1890/15-0642.1/suppinfo 